\title{
OS ELEMENTOS REPUBLICANOS NA TOLERÂNCIA DE JOHN LOCKE
}

\author{
Antônio Carlos dos Santos* \\ acsantos12@uol.com.br
}

RESUMO John Locke é conhecido, sobretudo, por ser um dos fundadores do liberalismo. No entanto, pesquisas recentes apontam para novas interpretações do pensador inglês. No caminho dessa tendência, o objetivo deste texto é analisar os elementos republicanos na "Carta sobre a tolerância" de Locke.

Palavras-chave Tolerância, Locke, republicanismo.

ABSTRACT John Locke is mainly known for being one of the founders of Liberalism. However, recent research points to new interpretations of the English thinker. On the way of this trend, the aim of this paper is to analyze the republican elements in the "Letter on Toleration" of Locke.

Keywords Toleration, Locke, republicanism.

\section{Introdução}

Entre 1689 e 1690, John Locke publica três livros. Um de natureza epistemológica, outro política, e, por fim, político-religiosa. Respectivamente, no "Ensaio sobre o entendimento humano", registra: 
A necessidade em que nos encontramos de acreditar sem conhecimento e, muitas vezes, até sobre fracos fundamentos, no estado passageiro da ação e da cegueira em que vivemos sobre a terra, esta necessidade, digo eu, deveria tornar-nos mais cuidadosos em nos instruirmos a nós mesmos do que em obrigar os outros a aceitar as nossas opiniões. (parte IV, cap. 16, § 4)

No "Segundo tratado do governo civil", afirma Locke: "é legítimo para o povo resistir a seu rei" (Locke, 1959, p. 232); e, na "Carta sobre a tolerância”, assevera: “[...] nenhum indivíduo deve atacar ou prejudicar de qualquer maneira a outrem nos seus bens civis porque professa outra religião ou forma de culto. Todos os direitos que lhe pertencem como indivíduo, ou como cidadão, são invioláveis e devem ser-lhe preservados. Estas não são as funções da religião" (Locke, 2010). ${ }^{2}$ Ora, o que há de comum nessas obras? Qual o traço característico que permeia esses textos?

Podemos notar, entre outros aspectos, na primeira obra, um questionamento sobre a certeza do conhecimento e a natureza do entendimento; na segunda, os limites do poder político e a sua legitimidade; e, finalmente, na terceira, a reivindicação do direito de tolerância, seja enquanto indivíduo, seja enquanto cidadão. Nossa hipótese é que podemos pensar esse bloco de obras lockeanas sob a perspectiva da tolerância levando em consideração a matriz teológicopolítica: ${ }^{3}$ na primeira se encontra o uso individual e racional do entendimento, na segunda, a organização política e, na terceira, a convivência com o outro do ponto de vista político-religioso. Nelas, a nosso ver, está em jogo o problema da ação política, ${ }^{4}$ que passa pelo conhecimento de si, pela relação institucional com os outros e, finalmente, com os valores que cada um elege para si. Não podemos entender a tolerância em Locke descolando estes três aspectos.

Locke é conhecido, sobretudo, por ser um dos fundadores do liberalismo político. ${ }^{5}$ No entanto, a bibliografia mais recente tem apontado novas interpretações sobre o tipo de liberalismo de Locke, uma vez que há certos aspectos do seu pensamento nos quais flerta com o republicanismo. Huyler, por exemplo, defende essa interpretação, embora de uma forma largamente tímida: "Se

1 Na tradução para o português, ver: Locke, 1998, p. 588. Doravante, autor, obra e número do tópico.

2 Na tradução para o português, ver: Locke, 1984, p. 6.

3 Por matriz teológico-política, entendemos o corpus de ideias segundo o qual as ações políticas e sociais humanas têm origens transcendentes, e as leis divinas, na condição de leis reveladas, são consideradas políticas, dificultando o exercício da liberdade e do pensamento, além de conduzir os indivíduos numa obediência cega ou numa "servidão voluntária", para lembrar a célebre expressão de La Boétie.

4 Esta ideia é a base da interpretação de Richard Ascraft. No entanto, como indica o próprio título de sua obra, ele se dedica aos "Dois tratados do governo civil", muito embora faça alusão às outras obras de Locke. Cf. Ascraft, 1995.

5 Sobre esta temática, a bibliografia é vasta. Destacaríamos apenas: Strauss, 1953; Macpherson, 1962; Grant, 1991; Eisenach, 1981; Biziou, 2010. 
a vida de Locke e seus escritos exemplificam liberalismo, então pelo menos o projeto liberal está em conformidade com o plano republicano em praticamente todos os detalhes" (Huyler, 1977, p. 533). Ora, se for verdade a ideia segundo a qual com aquelas obras John Locke é considerado um dos fundadores do liberalismo, não é menos verdadeiro que elas apresentam traços do republicanismo moderno. Como sabemos, uma das características dessa forma política é a ausência de domínio externo ou sua aversão à tirania, por um lado, e a participação dos homens na res publica, por outro. ${ }^{6}$ Numa fórmula simples, o regime republicano seria o domínio da lei e do direito do cidadão, ao passo que o liberalismo, o do comércio e do indivíduo com fortes lastros democráticos. A preocupação de Locke com relação à obediência civil (sobretudo quando se trata de leis legítimas), à liberdade, à tolerância, à resistência ao despotismo e por isso o limite do poder político (o que não pode ser confundido com a ideia do estado mínimo), entre outras questões, nos indica um retrato de seu republicanismo moderno, ${ }^{7}$ ao mesmo tempo que apresenta elementos do liberalismo ${ }^{8}$ nascente, tais como a proteção da propriedade privada, a liberdade do comércio e a pouca intervenção estatal. Mas seu liberalismo não se reduz à proteção do mercado tanto quanto seus traços republicanos não são puramente cívicos. Locke, então, parece indicar um republicanismo mitigado. ${ }^{9}$

Contudo, algumas questões são inevitáveis: os traços republicanos de Locke não se chocariam com os elementos liberais? Se o republicanismo enfatiza o dever e o liberalismo o direito, não haveria aí uma tensão difícil de ser conciliada? Como pensar interesse comum e individual ao mesmo tempo em Locke?

6 Segundo Sérgio Cardoso, "República se diz, então, sobretudo dos 'regimes constitucionais', daqueles em que as leis e regulações ordinárias, bem como as disposições do governo, derivam dos princípios que conferem sua forma à sociedade e em que tais estabelecimentos, postos acima de todos, a protegem de todo interesse particular ou transitório, de toda vontade caprichosa ou arbitrária" (cf. Cardoso, 2004, p. 45).

7 Grosso modo, o republicanismo é uma tradição de pensamento político que remonta suas origens à Roma antiga, sobretudo a Cícero, e ressurge no mundo renascentista com os humanistas cívicos e com Maquiavel. Sobre as origens do republicanismo, ver: Bignotto, 2001. E, sobre o republicanismo clássico, ver: Skinner, 1998.

8 É uma tradição política que remonta ao século XVII, de tradição anglofone (Inglaterra e, posteriormente, Estados Unidos), na qual o Estado é limitado, distante das esferas religiosas. Ela permite aos sujeitos desfrutarem a liberdade, a igualdade de condições e a felicidade individual na medida em que ele (o Estado) não interfere nas suas vidas. Liberdade e igualdade são, pois, seus princípios fundamentais. Segundo Audard, "a tese central do liberalismo pode se resumir numa fórmula: não existe subordinação natural dos seres humanos e cada indivíduo é soberano e livre em decidir por si mesmo face a todas as autoridades, morais e religiosas, [...] que queiram se submeter" (Audard, 2009, p. 69).

9 Sobre a relação entre os humanistas cívicos e pensadores republicanos ingleses e americanos, ver o clássico: Pocock, 1975. 
Assim, nosso objetivo é analisar os elementos republicanos lockeanos, ou seja, aqueles aspectos típicos do regime republicano, que dizem respeito à liberdade, ao direito e à ação política. No entanto, limitar-nos-emos única e exclusivamente aos argumentos da "Carta sobre a tolerância", a fim de não extrapolarmos os limites estabelecidos para este artigo. Com a análise que segue, esperamos ultrapassar a ideia bastante conhecida de um Locke apenas fundador do liberalismo para pensarmos num Locke que tenha profundos laços com o republicanismo moderno. Para levarmos a bom termo esse plano, este texto está dividido em duas partes: na primeira, serão abordados os conceitos fundamentais de republicanismo e liberalismo e, na segunda, uma análise dos elementos propriamente republicanos na "Carta sobre a tolerância" de Locke.

\section{I}

No livro V, capítulo 19 do "Espírito das Leis", Montesquieu faz um enorme elogio à organização política inglesa porque ela funciona "como se fosse uma república". Segundo o autor de La Brède, o que fez da Inglaterra uma espécie de "atualização" da Atenas antiga foi o exercício do poder do povo por meio do Parlamento (governo representativo), o respeito às leis, a separação dos poderes, a estabilidade política e a tolerância, primordialmente. Como ele não se cansa de repetir, a república é um regime do passado: Grécia, Roma ou, no máximo, as repúblicas italianas como Gênova e Veneza, foram exemplos bastante isolados. Montesquieu não elegeu um regime ideal: ele fez uma escolha por exclusão. O regime despótico é corrupto por natureza, a república é coisa do passado e a monarquia tem que ser a temperada, jamais absoluta. Ora, a Inglaterra - sobretudo após a experiência de sua guerra civil, e em particular o curto período republicano de Cromwell - passou a ser uma espécie de modelo para as monarquias que não se identificavam mais com a visão absolutista. Talvez, mais do que apontar um modelo para o mundo moderno, Montesquieu admire a Inglaterra porque ela conjuga o interesse econômico, próprio do liberalismo, e o político, mais próximo do republicanismo.

Sérgio da Costa demonstra que o cidadão moderno se define pelo direito à propriedade e ao contrato, mas também pela participação política, de tal forma que o bourgeois e o citoyen se encontram no espaço comum (Costa, 2002 , p. 22). É verdade que esta separação não é tão estanque assim, tendose em vista que há uma divisão dentro do próprio liberalismo: um político e outro econômico. O primeiro é mais avançado em termos de direito, ao passo que o segundo é mais conservador em relação a esses mesmos direitos; aquele está mais voltado à igualdade dos cidadãos, enquanto o último à liberdade 
individual. Se pudéssemos resumir numa sentença, diríamos mais ou menos assim: o liberalismo político se vincula mais estreitamente à tradição republicana, mas o econômico se afasta largamente, uma vez que, nele, o fator preponderante é a liberdade individual. ${ }^{10}$ No entanto, não podemos nos esquecer também que o mesmo princípio que assume a possibilidade de liberdade e igualdade política permite que se pense a origem da propriedade e das relações econômicas.

Tradicionalmente, um dos traços mais característicos da problemática republicana e liberal é a liberdade. Desde 1814, quando Benjamim Constant escreveu "A liberdade dos antigos comparada à dos modernos" (Constant, 1980), que a discussão em torno da liberdade tem feito surgir novas interpretações. Na sua versão contemporânea, Isaiah Berlin, em 1958, publicou um ensaio sobre a liberdade, que faz uma reinterpretação do ensaio de Constant, e continua bastante polêmico (Berlin, 1969). ${ }^{11}$ Segundo Berlin, há duas versões sobre o conceito de liberdade: uma, negativa, em que o Estado não deve interferir nos assuntos dos indivíduos, exceto para proteger seus bens, e outra positiva, vinculada mais aos direitos políticos, sobretudo à democracia. Em outras palavras: o republicanismo combina com a democracia, mas o liberalismo econômico, não necessariamente. $\mathrm{Na}$ interpretação de Bresser-Pereira, a liberdade negativa significa "estar livre de", e a positiva, "estar livre para". Ainda segundo esse comentador, "os cidadãos têm a liberdade negativa de não estarem sujeitos a restrições ou interferências em seus legítimos desejos ou interesses; têm a liberdade positiva de participar do governo, compartilhar do bem público ou comum, e resistir às tentativas de indivíduos particulares de se apoderarem do patrimônio público" (Bresser-Pereira, 2004, p. 138). Nessa interpretação liberal, a liberdade negativa é valorizada em detrimento da positiva, que é vista como perigosa. Como diz o próprio Berlin (1969, p. 131), a liberdade positiva é, "por vezes, não mais do que um disfarce capcioso para a tirania brutal".

Uma interpretação da ideia de liberdade moderna, que toma relativa distância seja de Constant seja de Berlin, é a de Pettit (1977). Para esse autor, seria possível conceber a liberdade como ausência de dominação, e não como interferência, como pensa Berlin, sobretudo. Dominação, segundo o francês, é quando o agente tem capacidade de interferir e imperar na vontade dos outros, e estes poderiam reagir sem coerção. Assim, a lei terá importância fundamental porque ela não vai dominar, mas restringir o raio da ação. Nas palavras de 
Pettit, "se há dominação, mas nenhuma interferência, como no caso do amo que não interfere, apenas o ideal de não dominação encontrará alguma coisa para denunciar" (ibidem, p. 23). Ou seja, segundo o intérprete, os republicanos não priorizavam a participação, mas a não interferência.

Ora, é verdade que a interpretação de Pettit tem o mérito de abrir o leque de discussão sobre o conceito de liberdade para além dos dois modelos propostos por Berlin na medida em que busca relacionar liberdade e igualdade. A dificuldade está no fato de tal leitura não nos permitir escapar da mesma armadilha da visão liberal, que o próprio Pettit critica em larga medida. Em dois pontos, ao menos, sua visão é restritiva. Primeiro, porque esse autor esvazia o conceito de liberdade naquilo que ele tem de mais positivo: a participação política, uma vez que restringe a ação política dentro da legalidade estritamente formal. O resultado disso, como diz o próprio Pettit (2003, p. 59), "é que os indivíduos só têm liberdade no silêncio das leis, lá onde a lei não intervém". Em segundo lugar, a concessão de direitos não assegura necessariamente a igualdade, seja ela econômica ou social, e por isso o problema da inclusão continua aberto. No caso de uma ação legítima, então isso significa que houve consentimento de todos (ou da maioria) para que toda e qualquer intervenção do governo sobre "minha pessoa" fosse permitida: é a interferência para "meu próprio bem", diferente da interferência arbitrária, para a qual não há "meu consentimento". No entanto, Petitt alarga essa concepção ao prever que o consentimento que legitima a intervenção hoje pode não valer para intervenções futuras, donde se justificaria a necessidade de se rever o próprio consentimento. No fundo, Pettit afirma a necessidade de que, para haver liberdade, é preciso haver contestabilidade, isto é, possibilidade de questionar as intervenções futuras a fim de que a interferência não se torne dominação. ${ }^{12}$

Para escapar tanto da armadilha liberal de Berlin quanto da visão do republicanismo contemporâneo proposto por Pettit, Bignotto propõe outra via: a do humanismo cívico. Isto porque, segundo ele, "o conceito de república se referia a uma ordenação jurídica precisa e que tinha por base a possibilidade de participação dos cidadãos nos negócios da cidade e à estabilidade das regras que regiam essa participação" (Bignotto, 2004, p. 28). Para este intérprete, pensar o republicanismo pela via do humanismo cívico nos faz pensar a vida pública no seu conjunto e não apenas os indivíduos isolados, senhores de direitos e de deveres. $\mathrm{O}$ argumento central do republicano é que o par ação e contingência faz parte do mesmo processo da ação humana no mundo, tanto presence for those of a certain marginalized ethnicity or culture or gender" (Pettit, 1977, p. 63). 
do ponto de vista material quanto do simbólico (ibidem, p. 37). Retomando os conceitos de virtù e fortuna segundo Maquiavel, Bignotto demonstra que agir na cidade não é apenas um problema de deliberação, como insistem os liberais, mas muito mais uma questão de convicção. Daí que a própria ação do homem sobre o mundo se converte em princípios que vão reger a ação de seus cidadãos.

Ciente dos limites do republicanismo contemporâneo, Bignotto não deixa dúvida de que não se pode ficar num saudosismo da república antiga e desconsiderar por completo os limites de uma participação política ativa no mundo hodierno. Se, por um lado, pode haver democracia sem a participação constante da massa na cena política, por outro, essa ausência do povo pode ameaçar a própria liberdade que se impõe como central nesta discussão. Em suas palavras, "na ótica republicana, o político se funda no conflito constante das partes que compõem o corpo político e ganha seus contornos institucionais e históricos na medida em que se chega a uma configuração de direito que os acolhe" (Bignotto, 2004, p. 39). Assim, o campo da ação política está impregnado de imprevisibilidade e de incertezas, e as experiências revolucionárias demonstraram claramente isso. O que o republicanismo nos ensina, enfim, é que não podemos prescindir da experiência eterna de cuidar do conflito público num espaço de liberdade em que os desejos individuais são postos à prova.

Se o passado das repúblicas antigas se mostrava glorioso, como pensa Montesquieu, os modernos "só pensam no comércio" e por isso, afirma ele referindo-se à Inglaterra, "a república se esconde sob a forma da monarquia" (1998, V, 19). Aqui, o ideal republicano de bem comum se conjuga com a emancipação das paixões humanas, materializada na vontade do indivíduo, nos espaços que a lei permite. Esta ideia, que já estava presente em Locke, ganha novos contornos se pensarmos que a ação do indivíduo não é meramente uma obediência à lei, mas a certos princípios, como o da liberdade, que, quando a própria lei é violada, poderão iluminar novas ações. A teoria da tolerância em Locke é um bom caminho para pensamos estas questões.

\section{II}

Em janeiro de 1690, John Locke escreve uma carta ao pai na qual demonstra toda a sua angústia e preocupação com os acontecimentos na Inglaterra no período. Diz ele:

Nestes tempos, quando não existe segurança contra as paixões e as vinganças dos homens serão aquelas que a força e a ferro procuram, venho há tempos pensando que 
a melhor condição seja pegar as armas, coisa que teria feito, se pudesse estar certo de não dar o meu sangue só para acrescentar as fortunas dos outros homens e de não manchar-me com crimes por causa da ambição deles em aumentá-las. (De Beer, 1976, Vol. I, pp. 136-137)

Deste pequeno trecho da carta, duas coisas são notáveis: a primeira, a constatação da insegurança, das facções que dividem opiniões, e a segunda, a disposição em pegar nas armas se este esforço fosse revertido em benefício coletivo, e não apenas para alguns. A falta de segurança justificaria a mão armada, o que vemos aqui é um Locke que flerta com o pensamento hobbesiano. Mas esta sua verve revolucionária é acompanhada de boa dose de cautela, pois, continua o missivista:

As armas são o último e o pior refúgio. A grande desventura desta nação destruída e fora de si é que as guerras não têm produzido nada além das guerras e que a espada só deu trabalho à espada. [...] Queria estar em paz e em segurança: se, porém, não me for dada a satisfação de ter ambas as coisas juntas, esta última, certamente, deve ser conseguida a todo custo [...]. Apenas desejo isto: que não arrisqueis mais a saúde e os bens que te sobraram para favorecer homens ingratos, como os ambiciosos; de homens falsos como os que prometem a liberdade. (De Beer, 1976, Vol. I, pp. 136-137)

É importante destacar que seu pai havia militado no Exército de Cromwell, donde se justifica a exortação para não arriscar sua segurança e bens em nome de uma liberdade incerta. Se de um lado Locke justifica que é lícito lutar e arriscar a vida pela liberdade, de outro ele deixa claro que estes ideais devem ser acompanhados de um bônus, a segurança. Mas não só: talvez Locke queira sugerir que o preço que pagamos pela liberdade só vale a pena na medida em que temos segurança, a qual jamais se dissocia dos próprios bens. Esta preocupação com a segurança, a vida e os bens é central na primeira obra sobre a tolerância, escrita do ponto de vista filosófico.

$\mathrm{Na}$ "Carta sobre a tolerância", podemos notar três fortes argumentos a favor da tolerância. O primeiro, de caráter religioso, justifica que a tolerância não é contrária ao Evangelho, ou seja, que mesmo lá vemos fortes sinais de que a religião nos ensina certos valores, como o amor a Deus e ao próximo, e que por isso não haveria necessidade de se odiar o outro somente pelo fato de ele professar uma religião diferente da nossa. É verdade que este argumento, ainda tímido, não convence muita gente, sobretudo num ambiente religioso bastante hostil como o da Inglaterra naquele momento, em que as várias facções religiosas disputavam espaços políticos e religiosos.

O segundo aspecto, de caráter político, é demonstrar que a diversidade de opinião não pode ser causa de guerra e de discórdia política, muito menos 
religiosa. ${ }^{13}$ Nesse ponto, Locke entende que o problema da tolerância era muito mais político do que religioso, e que uma de suas causas era a unidade política e não necessariamente a religiosa. Ou seja, o domínio de uma única religião que pudesse unificar o reino poderia levar este reinado ao absolutismo - ponto de maior resistência dos ingleses. A tentativa de unidade religiosa implicaria um convertimento à força, e Locke é taxativo: em matéria de religião, só o convencimento é eficaz, jamais a força, pois ele se vincula à concepção de fé e à legitimidade da crença. Por isso, defende Locke:

Se os homens são submetidos a ferro e fogo a professar certas doutrinas, e forçados
a adotar certa forma de culto exterior, mas sem se levar em consideração seus
costumes; se alguém tentar converter os de fé contrária, obrigando-os a cultuar coisas
nas quais não acreditam, e permitindo-lhes fazer coisas que o Evangelho não permite
aos cristãos, e que nenhum crente permite a si mesmo, não duvido que apenas visa
reunir numa assembleia numerosa outros adeptos de seu culto; mas quem acreditará
que ele visa instituir uma igreja cristã? (Locke, 1984, p. 2)

Finalmente, o último argumento, este mais institucional, é o da separação dos poderes e da delimitação das tarefas e competências do Estado e da Igreja. Defende Locke: "a sociedade política foi instituída unicamente para assegurar a cada pessoa a posse de coisas desta vida, e com nenhum outro propósito. O cuidado da alma e de assuntos espirituais, que não pertencem e não se subordinam ao Estado, é reservado e mantido por cada indivíduo" (ibidem, p. 19). Ou seja, para Locke, a tarefa do poder político é preservar as coisas terrenas e, a da Igreja, o cuidado com os assuntos espirituais. O cidadão se ocupa dos assuntos públicos; o indivíduo, dos assuntos privados, como o da salvação. É importante notar que este argumento permitiu, finalmente, que a tolerância tomasse cena pública, não mais como um assunto privado, de consciência, mas tivesse um caráter institucional, de Estado.

Ao separar as tarefas políticas e religiosas, Locke confina os problemas religiosos na esfera privada, e passa a reivindicar ao Estado a liberdade, a preservação da vida e de seus bens, porque em última instância é o Estado que se ocupa da relação entre o indivíduo e o cidadão. Por isso, defende Locke: "Nenhum indivíduo deve atacar ou prejudicar de qualquer maneira a outrem nos seus bens civis porque professa outra religião ou forma de culto. Todos os direitos que lhe pertencem como indivíduo, ou como cidadão, são invioláveis e devem ser-lhe preservados" (ibidem, p. 6). Aqui, três temas se

13 Diz literalmente Locke: "Não é a diversidade de opiniões (o que não pode ser evitado), mas a recusa de tolerância para com os que têm opinião diversa, o que se poderia admitir, que deu origem à maioria das disputas e guerras que se têm manifestado no mundo cristão por causa da religião" (Locke, 1984, p. 24). 
entrelaçam: liberdade (de culto), preservação (dos bens) e direito (tanto do indivíduo quanto do cidadão). Ora, a tradição da política moderna relacionou esses três aspectos da vida moderna como se fossem única e exclusivamente características do liberalismo, como se não tivesse nenhum laço que os vinculasse ao republicanismo, ou, quando houvesse, só fosse percebido pelo viés negativo, como faz Berlin, sobretudo na questão da liberdade lockeana.

Como sabemos, a liberdade em Locke faz parte da propriedade do homem, juntamente com a vida e seus bens, e caberá ao governo civil preservá-la. Ele insiste que todo homem "tem direito à liberdade de sua pessoa" (Locke, 1998, sec. 190), mas também deixa claro que, para que todo homem seja livre do domínio de terceiros, é preciso que haja leis, que se tornam a condição da liberdade. Segundo suas palavras, "liberdade é estar livre da restrição e da violência dos outros" (ibidem, sec. 57). Isto significa dizer que nos tornamos livres pela racionalidade e nos preservamos em virtude das leis que instituímos dentro da legalidade. Por esta razão, conclui Locke: "a finalidade da lei não é abolir a liberdade nem restringi-la, mas preservá-la e ampliá-la” (idem). Mas esta liberdade não terá o efeito desejado se não for acompanhada do entendimento.

No "Ensaio sobre o entendimento humano", Locke define liberdade como o poder humano para agir ou não agir "de acordo com a preferência da mente" (Parte II, cap. 21, § 12). Segundo ele, ainda nessa obra, somos livres na medida em que temos a capacidade de agir, de fazer escolhas, de preferir por meio de nossa mente, que se manifesta pela vontade. A vontade é um poder que o homem tem, que é exercido enquanto agente. Como afirma o próprio Locke, "é a mente que opera e exerce esses poderes; é o homem que realiza essa ação; é o agente que tem esse poder" (Parte II, cap. 21, § 19). Mas o que delibera sobre a ação que temos que executar? Devemos fazer uso de todo nosso poder de agir? Devemos dar vazão a toda a nossa vontade? Segundo Locke, é evidente que não. Para ele, cabe a nós questionar a ação, suspendê-la ou simplesmente nos manifestar opostos ao "guia da razão". Ou seja, é graças a este guia, que é uma espécie de um conjunto de regras que o homem constrói para si, que não cerceia o poder que ele próprio tem: este guia é a liberdade.

Pensando nesta perspectiva, o conceito de liberdade lockeana está diretamente ligado ao entendimento e à moralidade porque Locke está interessado num critério que vai fundamentar sua ação. Como defende Vienne,

A liberdade é então o centro da reflexão e da ação política de Locke. [...] Assustado pelos conflitos das igrejas que se rivalizavam dogmaticamente, ele tenta manter os direitos de um pensamento individual e crítico contra a intolerância. Sua ação ao lodo 
de Shaftersbury e sua reflexão teórica durante os momentos do exílio, levam-no a pensar no lugar da liberdade na política. (Vienne, 1991, p. 216)

Por esta razão, não podemos dissociar a publicação da "Carta sobre a tolerância" do contexto teológico-político no qual a obra foi concebida e publicada. Em resumo, a liberdade exige uma reflexão sobre a ação, de tal maneira que esta ação precisa ser moralmente boa ou eticamente justa, uma vez que é fruto de um entendimento. A liberdade, assim, ganha conotação ao mesmo tempo de direito (natural) e de dever (do indivíduo). Ora, esses dois lados da mesma moeda denotam que a liberdade é instituída na medida em que ela é amparada pela lei, o que significa dizer que a lei não veio para restringir a liberdade, mas para permitir que ela exista em condições de existência bastante razoáveis.

Não podemos entender o sentido da tolerância em Locke sem relacioná-la com a liberdade de uma consciência individual e dos princípios morais e políticos que estão nela envolvidos. Neste sentido, a tolerância é fruto de uma moralidade que é construída individualmente, e cabe a cada um justificá-la para si mesmo enquanto artifício intelectual. Mas este processo por si não tem sentido se não for acompanhado de leis instituídas que definam as tarefas e competências do Estado e da Igreja e que obriguem essas instituições a cumprirem essas mesmas regras do ponto de vista político. Temos, assim, tarefas internas, que cabem ao indivíduo, e outras externas, que cabem às instituições. A paz religiosa é possível porque o indivíduo se une aos demais em função também de seus próprios interesses, não apenas por conta das consequências públicas, mas sobretudo porque ele é um ser moral, cujos princípios estão na razão, fruto do seu entendimento. ${ }^{14}$ Ora, conforme vimos, o entendimento é o lugar da liberdade. Se as instituições ultrapassarem seus limites, a vontade humana saberá proporcionar nova tomada de decisão: seja com base na lei, seja ultrapassando-a, se ela não for legalmente válida.

Consciente de seus próprios atos, assumindo suas responsabilidades a partir de seu interior, o indivíduo lockeano se transforma em "pessoa": é o único lugar de imputabilidade do mérito ou de culpa definida pelo "eu interior" ("Ensaio", Livro 2, cap. 27). É ali que se encontra o âmago da vida moralmente livre e justa, com implicações diretas na ideia de tolerância. Neste sentido, afirma Locke na "Carta sobre a tolerância":

14 Esta concepção de Locke, mais idealista, vai permanecer até sua última obra, "The Reasonableness of Christianity". A partir dela, a religião simples vai assumir o papel de elemento primordial da moralidade, acima do uso da mera razão. 
Se um judeu não acredita que o Novo Testamento é a palavra de Deus, em nada altera quaisquer direitos civis. [...] O poder do magistrado e as propriedades dos cidadãos estão igualmente assegurados se alguém acredita ou não nessas coisas. [...] Não cabe, todavia, às leis fundamentar a verdade das opiniões, mas tratar da segurança e proteção da comunidade e dos bens de cada homem. (Locke, 1984, p. 17)

O que Locke mais insiste é que uma vez delimitadas as esferas e competências das instituições, por um lado, e o entendimento individual que é possível conviver com religiões diferentes, por outro, a tolerância se constitui como algo simples, quase corriqueiro. E se excessos forem detectados, por qualquer parte, haverá sempre um espaço de discussão ou de resistência, seja do ponto de vista do cidadão, seja do ponto de vista do indivíduo.

\section{Considerações finais}

Se a visão da tradição liberal atribuía a Locke, de modo particular, o deslocamento normativo das ações humanas para o campo do direito, sobretudo no que tange à liberdade tida como "negativa", uma visão mais ampla do pensamento lockeano que envolva as três obras aqui elencadas permite-nos pensar a teoria da tolerância para além do modelo jurídico-liberal. A retomada da tradição republicana pode nos ajudar a pensar Locke sob o ponto de vista da liberdade, da ação política e do direito, o que estamos chamando aqui de "elementos republicanos", ${ }^{15}$ sem reduzir estes conceitos à visão liberal ou mesmo ao jusnaturalismo. O pensamento lockeano não apresenta os mesmos conceitos liberais econômicos que Adam Smith defende, por exemplo, em “A riqueza das nações", de 1776. Maurizio Viroli (2002, p. 61) afirma que "o liberalismo pode ser considerado um republicano empobrecido ou incoerente [...]. O republicanismo é uma teoria liberal que é mais radical e consistente do que o liberalismo clássico". A novidade de Locke está em transferir a doutrina da liberdade natural em doutrina da resistência política passando o poder para as mãos do indivíduo. Deste ponto de vista, no que diz respeito à tolerância, é possível que John Locke tenha sido o maior dos republicanos no século XVII: pensou a liberdade política e religiosa num ambiente bastante hostil, defendeu a ação política, mesmo quando o direito não nos era favorável, e possibilitou uma nova ordem política na qual a igualdade das leis permite

15 Locke, ao menos na obra aqui analisada, silencia sobre os republicanos de seu tempo, especialmente os mais radicais, como Milton. Talvez pelas experiências negativas que essa forma política deixou na Inglaterra no período de Cromwell, embora haja registro que alguns livros de Milton constem na de Locke. De qualquer modo, o direito dos indivíduos à resistência a seus governantes tirânicos está presente tanto em Milton quanto em Locke. 
condições constitucionais de proteção contra qualquer tipo de servidão. Liberdade religiosa, direito de resistência e supremacia do Parlamento formam assim uma espécie de tríade republicana que vai marcar o pensamento político moderno.

Assim, a tolerância afasta-se da violência, relativiza os dogmas religiosos, limita o poder religioso e político, promove a proteção à vida e à liberdade de seus indivíduos. Tradicionalmente o liberalismo foi vinculado ao individualismo de tal forma que este foi pensado de forma atomizada, sem elo social, esquecendo-se que em Locke os indivíduos são sociáveis e unidos pela lei natural, e fortalecidos pelo contrato, razão pela qual eles podem resistir à opressão do Estado, se necessário for. Se é verdade a afirmação segundo a qual o liberalismo é "um canto à glória da liberdade sob todas as suas formas", como diz Moreau (1978, p. 7), então a tolerância é a face mais visível do liberalismo lockeano. Locke não é um liberal no pleno sentido da palavra, mesmo porque o próprio termo liberalismo surgiu muito tardiamente, mas também não podemos denominá-lo um pensador republicano. Neste sentido, devemos ser prudentes: embora a política liberal represente, defenda, contorne problemas coletivos e interesses individuais, ela visa a solucionar conflitos relativos ao bem comum, como o problema da tolerância (Raynaud, 2010). Por esta razão, a tolerância lockeana é essencialmente pluralista porque cada um está persuadido de que a melhor saída para os conflitos é respeitar a diversidade religiosa, as crenças e práticas de cada um, desde que não ponha em risco a paz civil, tampouco se imponha uma verdade absoluta, mesmo secularizada, científica ou racional. Aqui, o consenso se dá pelo viés da paz comum, não em torno da verdade coletiva, razão pela qual o espaço público exige o pluralismo de toda ordem, inclusive, o da ação política. Nele, os indivíduos não são atomizados, mas se reconhecem como sujeitos políticos: eis um dos traços mais marcantes do republicanismo lockeano. Talvez Montesquieu tenha razão: a Inglaterra está impregnada de elementos republicanos e seria muito importante que não a perdêssemos de vista.

\section{Referências}

ASCRAFT, R. "La politique révolutionnaire et les Deux traités du gouvernement de John Locke". Paris: PUF, 1995.

AUDARD, C. "Qu'est-ce que le libéralisme?". Paris: Gallimard, 2009.

BERLIN, I. "Two concepts of liberty". In: . Four Essays on Liberty. Oxford: Oxford University Press, 1969.

BIGNOTTO, N. “Origens do republicanismo moderno". Belo Horizonte: Ed. UFMG, 2001. 
. "Problemas atuais da teoria republicana". In: S. Cardoso (org.). Retorno ao republicanismo. Belo Horizonte: Ed. UFMG, 2004.

CARDOSO, S. "Por que república? Notas sobre o ideário democrático e republicano". In: S. Cardoso (org.). Retorno ao republicanismo. Belo Horizonte: Ed. UFMG, 2004. BRESSER-PEREIRA, L. C. "O surgimento do Estado republicano". Lua Nova, Nr. 62, 2004.

BIZIOU, M. “À l'articulation du liberalism politique et du liberalism économique: le jugement individual face à l'État chez Locke et Smith”. In: G. Kévorkian. La pensée libérale. Paris: Ellipses, 2010. pp. 35-56.

CARDOSO, S. "Retorno ao republicanismo". Belo Horizonte: Ed. UFMG, 2004. COSTA, S. "As cores de Ercília". Belo Horizonte: Ed. UFMG, 2002.

CONSTANT, B. "De La liberté chez les modernes: écrits politiques". Ed. Gauchet. Paris: Flammarion "GF", 1980.

DE BEER, E. S. (ed.). "The correspondence of John Locke". Vol. I, pp. 136-137. Oxford: Oxford Press University, 1976.

EISENACH, E. J. "Two Worlds of Liberalism religion and politics in Hobbes, Locke and Mill". Chicag; London: The University of Chicago Press, 1981.

GRANT, R. W. "John Locke's Liberalism". Chicago; London: The University of Chicago Press, 1991.

HUYLER, J. "Was Locke a Liberal?". The Independent Review, Vol. 1, Nr. 4, pp. 523-542, 1977.

LOCKE, J. "Works". Aalen: Scientia, 1963.

. “An Essay Concerning Human Understanding”. Edited by A. C. Fraser. New York: Dover Publications, 1959.

. "An Essay Concerning Toleration". Edited by Milton and Milton. Oxford: Clarendon Press, 2010.

. "Carta sobre a tolerância". São Paulo: Abril Cultural, 1984.

. "Dois tratados sobre o governo". Tradução de Julio Fischer. São Paulo:

Martins Fontes, 1998.

. "The Reasonableness of Christianity". In: Writings on religion. Edited by V.

Nuovo. Oxford: Claredon Press, 2002.

. "Segundo tratado do governo civil". São Paulo: Martins Fontes, 1998.

MACPHERSON, C. B. "The Political Theory of Possessive Individualism”. Oxford: Oxford University Press, 1962.

MONTESQUIEU. “O Espírito das Leis”. São Paulo: Martins Fontes, 1998.

MOREAU, P-F. "Les racines du liberalisme". Paris: Seuil, 1978.

PETTIT, P. "Republicanism: A Theory of Freedom and Government". Oxford: Oxford University Press, 1977.

- "Liberalismo". In: Canto-Sperber (org.). Dicionário de ética e filosofia moral. São Leopoldo: EDUNISINOS, 2003. (Verbete, "Liberalismo").

POCOCK, J. G. A. "The machiavellian moment". Princieton: Princeton University Press, 1975. 
RAMOS, C. A. "O modelo liberal e republicano de liberdade: uma escolha disjuntiva?". Trans/Form/Ação, Vol. 34, Nr. 01, pp. 43-63, 2011.

RAYNAUD, P. “John Locke, fondateur du liberalisme?”. In: G. Kévorkian. La pensée libérale: histoire et controversies. Paris: Ellipses Éditions Marketing, 2010. pp. 2133.

SPITZ, J.-F. "John Locke et les fondements de la liberté moderne". Paris: PUF, 2001. SKINNER, Q. "Liberty befor liberalism". Cambridge: Cambridge University Press, 1998.

STRAUSS, L. "Natural Right and History". Chicago: University of Chicago Press, 1953.

VIENNE, J.-M. "Expérience et raison". Paris: PUF, 1991.

VIROLI, M. "Republicanism". New York: Hill and Wang, 2002. 